\title{
Avaliação institucional participativa e o diálogo com as categorias de Boaventura de Sousa Santos
}

\author{
Participatory institutional assessment and dialogue with the categories of \\ Boaventura de Sousa Santos \\ La evaluación institucional participativa y el diálogo con las categorías de \\ Boaventura de Sousa Santos \\ MARA REGINA LEMES SORDI \\ Orcid ld: http://orcid.org/0000-0003-1216-7185 \\ Universidade Estadual de Campinas
}

\begin{abstract}
Resumo: Analisa-se a política de avaliação institucional participativa implementada na rede municipal de Campinas com objetivo de identificar suas possibilidades emancipatórias a partir de categorias inspiradas em Sousa Santos. A base empírica do estudo envolve análise documental, observação e entrevistas com gestores das escolas. Confirma-se a potência dos processos avaliativos centrados na escola que valorizam o diálogo e a negociação com múltiplos atores envolvidos na construção da qualidade social da escola pública.
\end{abstract}

Palavras-chave: Avaliação Institucional; escola pública; qualidade social.

\begin{abstract}
It analyzes the policy of participatory institutional evaluation implemented in the municipal network of Campinas in order to identify its emancipatory possibilities from categories inspired by Sousa Santos. The empirical basis of the study involves documentary analysis, observation, and interviews with school managers. It confirms the power of schoolcentered evaluation processes that value dialogue and negotiation with multiple actors involved in the construction of the social quality of the public school.
\end{abstract}

Keywords: Institutional Evaluation; public school; social quality.

Resumen: Se analiza la política de evaluación institucional participativa implementada en la red municipal de Campinas con el fin de identificar sus posibilidades emancipadoras a partir de categorias inspiradas en Sousa Santos. La base empirica del estudio implica análisis documental, observación y entrevistas con los directores de la escuela. Se confirma el poder de los procesos de evaluación centrados en la escuela que valoran el diálogo y la negociación con múltiples actores involucrados en la construcción de la calidad social de la escuela pública.

Palabras clave: Evaluación institucional; escuela pública; calidad social. 


\section{INTRODUÇÃO}

É consensual a ideia de que a educação como política pública precisa ser avaliada. A avaliação em larga escala é uma das formas que o poder central usa para compilar evidências que possibilitem análise do que acontece com o conjunto das escolas do país, a fim de subsidiar a formulação de políticas educacionais. Seus princípios e métodos são pensados nesse escopo. Cabe às redes de ensino assumir titularidade na problematização contextual dos dados sistêmicos que recebe, evitando tomá-los como verdade absoluta ou desperdiçando-os. Ambas posturas merecem críticas.

Existem duas maneiras de entender a avaliação: a avaliação-comoregulação e a avaliação-como-emancipação. A convivência dessas formas nem sempre é pacifica na vida das escolas. Parafraseando Sousa Santos (1996), temos que a avaliação-como-regulação consiste numa trajetória entre um ponto de ignorância designado por caos e um ponto de conhecimento designado por ordem. A avaliação-como-emancipação consiste numa trajetória entre um ponto de ignorância chamado colonialismo e um ponto de conhecimento chamado solidariedade.

Como a forma "avaliação-como-regulação" ganhou primazia sobre a "avaliação-como-emancipação" nas atuais políticas educacionais, a ordem passou a ser a forma hegemônica de conhecimento e o caos a forma hegemônica de ignorância entendida como falta de qualidade. A hegemonia da avaliação-comoregulação permitiu a este paradigma recodificar nos seus próprios termos a avaliação-como-emancipação. A solidariedade foi recodificada como caos e o que era a ignorância transformou-se em saber (colonialismo recodificado como ordem).

Disso decorre que os referentes ético-epistemológicos mobilizados para orientar os modelos avaliativos ora em hegemonia conformam-se com uma escola pública cuja concepção de qualidade é reducionista (viés do colonialismo) e abstraída de valores, tais como a solidariedade entendida como ignorância (caos). Deriva desta tensão o surgimento de movimentos de contrarregulação. Políticas contrarregulatórias se confrontam propositivamente com lógicas de avaliação que dicotomizam processo-produto e que parecem mais afinadas com a qualidade mercadológica do que com a qualidade social da escola pública (FREITAS et al, 2009). 
A contrarregulação surge como expressão típica de subjetividades, individuais ou coletivas, que por entenderem os desdobramentos das políticas de accountabilitiy forte (AFONSO, 2012) no desenvolvimento humano dos estudantes, se mobilizam e atuam de modo a construir possibilidades para que a escola pública se organize na direção da qualidade social.

A avaliação institucional participativa (AIP) surge como uma das respostas estratégicas para inverter o sinal dessa equação, pois toma o projeto político pedagógico (PPP) da escola como referência mediadora entre os dados da avaliação externa e a avaliação das aprendizagens dos estudantes, considerados à luz dos compromissos com o entorno social e das condições objetivas em que opera. A articulação entre estes três níveis de abordagem avaliativa é crucial para a valoração circunstanciada da qualidade existente na escola.

A AIP pode ser entendida como espaço de resistência e opera construindo alternativas, historicamente pensadas, que potencializam o movimento das redes de ensino rumo a processos inteligentes de accountability (AFONSO, 2012). Permite que se interpelem os sentidos da avaliação externa sobre a organização do trabalho pedagógico da escola e seus desdobramentos nos estudantes. Sua força maior está no coletivo da escola a quem reconhece titularidade na definição dos rumos do projeto educativo por meio de um Pacto de Qualidade Negociada (BONDIOLI, 2004). A AIP se coaduna com processos de gestão democrática e se assenta na participação, no diálogo e na negociação entre os atores.

A rede municipal de Campinas, por meio da Secretaria de Educação (SME), adotou como política de governo a AIP em 2008, tendo sido assessorada neste projeto pela universidade pública local a qual coube, inclusive, a formação dos profissionais envolvidos. A AIP é regida por uma resolução que estabelece diretrizes para a implementação do processo em cada escola, que inclui a constituição de Comissões Próprias de Avaliação (CPA) com representantes de todos os segmentos em sua composição. O Orientador Pedagógico (OP), integrante da equipe gestora, é o responsável pela orquestração da AIP. A supervisão dessa política fica a cargo dos Núcleos de Ação Educativa Descentralizada (NAED), instância meso da rede. Uma Carta de Princípios, coletivamente formulada e disponibilizada no site institucional, explicita a opção pela avaliação formativa. A AIP nessa rede envolve ação conjugada entre escola e poder público e contempla reuniões de negociação que permitem diálogos em que os resultados são contrastados com as condições objetivas da escola, requerendo dos gestores centrais corresponsabilidade na produção da qualidade. A responsabilização compartilhada (SORDI; FREITAS, 2013) baliza o movimento da AIP. 
Processos de AIP fortalecem a organização dos coletivos escolares na luta pela qualidade da escola pública. A avaliação como processo intersubjetivo e expressão de práticas sociais conflituosas reconfigura-se para não constranger encontros entre atores, que mesmo diferentemente situados valorizam a comunicação e a participação plural que comporta o respeito à alteridade e a contratualização de estratégias que acenem para as possibilidades de mudanças coletivamente assumidas.

Este texto pretende estabelecer um diálogo entre essa política de AIP e categorias usadas por Boaventura de Sousa Santos, visando a revelar a complexidade que envolve a implementação de políticas educacionais de cunho participativo em contextos políticos nebulosos e extrair lições que subsidiem a defesa da qualidade da escola pública.

A base empírica do estudo pautou-se no banco de dados de pesquisa desenvolvida nesta rede, entre 2008-2017, financiada pelo OBEDUC/CAPES, e que envolveu entrevistas com equipes gestoras, grupo focal, observação de reuniões de negociação e de avaliação e análise documental (SORDI, 2018). O material foi qualitativamente tratado e organizado em categorias definidas a priori, baseadas em Sousa Santos, que nos desafia a partir das lições do passado, expandir o presente e contrair o futuro. Para expandir o presente, propõe uma sociologia das ausências; para contrair o futuro, uma sociologia das emergências mediadas por um trabalho de tradução, procedimento capaz de criar uma inteligibilidade mútua entre experiências possíveis e disponíveis sem destruir a identidade" (SOUSA SANTOS, 2006, p.95).

\section{AIP E OS DIÁLOGOS COM A SOCIOLOGIA DAS AUSÊNCIAS E DAS EMERGÊNCIAS}

A constituição de uma CPA em cada escola inscreve-se como estratégia para que a AIP se efetive e favoreça à comunidade o autoconhecimento capaz de visibilizar as contradições existentes entre o seu pensar e o seu agir. Destaca-se a relevância da ação mediadora do OP para fazer emergir o "entre" das coisas.

O "entre" aponta para um plano de constituição da realidade em que múltiplas forças se agenciam para compor e dar forma aos objetos formalizados e instituídos resultantes das práticas. (...) a avaliação pode desestabilizar os objetos instituídos e liberar, explicitar, potencializar as forças instituintes que estejam interferindo vivamente naquela realidade e que podem engendrar novas realidades. Existe nesta aposta, uma inseparabilidade entre avaliar e intervir (SANTOS FILHO et al 2011, p. 262). 
Consideramos a avaliação como categoria de ação que requer a disposição dos atores da escola para atuar sobre a realidade, gerando consequências a partir dos diagnósticos realizados. Ações de cunho contrarregulatório como a AIP exigem a superação dos álibis para o não agir, avançando na direção de um trabalho pedagógico socialmente referenciado.

Sousa Santos (2006) caracteriza diferentes razões para justificar a inação dos atores sociais. Destacamos, neste estudo, a razão impotente, que acredita que nada se pode fazer contra uma necessidade concebida como exterior a ela própria (determinismo) e a razão proléptica que não se aplica a pensar o futuro porque o concebe como uma superação linear do presente.

Contra estas posturas, o autor sugere a sociologia das ausências e das emergências.

Com a sociologia das ausências trata-se de demonstrar que o que não existe, é na verdade ativamente produzido como não existente, ou seja, alternativa não credível ao que existe. Há produção de não existência sempre que uma dada entidade é desqualificada e tornada invisível, ininteligível ou descartada de um modo irreversível (SOUSA SANTOS, 2006, p.102).

O ignorante, o inferior, o local, o residual e o improdutivo são justificativas engendradas para realçar o sentido da não existência e desqualificação das práticas de determinados atores sociais vistas como obstáculos em relação às realidades que contam como importantes (mais avançadas, superiores e produtivas).

Uma forma contra-hegemônica de avaliação luta pela visibilidade de todos os atores sociais na vocalização de seu entendimento sobre qualidade da escola. Os saberes e experiências de atores considerados inferiores ou ignorantes não podem ser subtraídos do debate sobre qualidade, tornados ausentes. "Tornarse presente significa serem consideradas alternativas às experiências hegemônicas, a sua credibilidade poder ser discutida e argumentada e as suas relações com as experiências hegemônicas poderem ser objeto de disputa política" (SOUSA SANTOS, 2006, p.104-105).

Sousa Santos propõe cinco ecologias (dos saberes, dos reconhecimentos, da temporalidade, da trans-escala e da produtividade) como formas de superação das condições que fundamentam sua crítica à razão indolente, seja na expansão do presente como na contração do futuro. Essas ecologias servem à contestação de posturas socialconformistas e podem potencializar políticas contrarregulatórias no campo educacional.

A ecologia dos saberes atua pondo em diálogo diferentes saberes que operam credivelmente nas práticas sociais. "Toda a ignorância é ignorante de um certo saber e todo o saber é a superação de uma ignorância particular” (p.106). 
O princípio da incompletude de todos os saberes é condição do diálogo entre diferentes formas de conhecimento, através das quais práticas diferentemente ignorantes se transformam em práticas diferentemente sábias. O investimento em relações horizontais entre os atores é fulcral para desestabilizar hierarquias existentes no contexto das práticas sociais historicamente produzidas.

As CPAs incorporaram essa ecologia, reconhecendo a legitimidade e incompletude dos saberes que os vários segmentos escolares possuíam. Em conjunto, foram aprendendo a examinar a complexa questão da qualidade da escola e a se posicionar na avaliação em nome desta qualidade tomada como referência. Práticas diferentemente ignorantes se transformavam em práticas diferentemente sábias. Destaca-se nesta ecologia a valorização dos saberes dos estudantes que assumem posições que se antes não lhes era proibido, a partir da AIP passam a ter maior compreensão de seu protagonismo na qualidade da escola.

A Ecologia das temporalidades parte da ideia de que as sociedades são constituídas por diferentes tempos e de que diferentes culturas geram diferentes regras temporais. Construir alianças e fortalecer ações coletivas entre movimentos ou organizações com diferentes regras temporais não é fácil. Organizações baseadas num tempo-horário monocrômico, descontinuo, concebido como um recurso controlado e de progressão linear têm dificuldades em compreender o comportamento político e organizacional de movimentos construídos segundo um tempo-acontecimento, policrômico, contínuo, que progride de forma não linear e vice-versa.

A AIP enraizava em cada escola os compromissos com a discussão permanente sobre a qualidade envolvendo todos os segmentos na construção de uma obra sempre incompleta. Toda obra construída coletivamente afeta a categoria tempo-espaço. Demanda momento e lugar para encontros regulares entre os atores, rigorosos e simultaneamente leves. A categoria tempo-espaço sinaliza a compreensão da historicidade dos processos locais; a impertinência de comparação descontextualizada dos avanços no cumprimento de metas; a aceitação de ritmos próprios para a adesão e apropriação das bases do trabalho avaliativo. A política de AIP é tributária de um tempo-acontecimento no qual o caminho da escola é traçado paulatinamente.

A Ecologia dos reconhecimentos recupera o princípio da igualdade e o princípio da diferença, "abrindo espaço para diferenças iguais, uma ecologia das diferenças feita de reconhecimentos recíprocos" (p.111-112) e se confronta com a desqualificação de determinados atores e das experiências sociais de que são protagonistas. 
Essa ecologia tencionou relações interpessoais instituídas na escola/SME pois, a título de exemplo, discussões de cunho pedagógico, antes mais restritas aos profissionais da educação, passaram a ser algo em que todos poderiam se manifestar. E decidir em conjunto. Relatada pelos OPs como uma lacuna nas reuniões das CPAs, as vozes de famílias, estudantes e funcionários, atores não comumente acostumados a pensar juntos o pedagógico, foram gradativamente se fazendo presentes na sua forma diferente, mas não inferior de olhar para o trabalho pedagógico da escola.

"Vejo que há participantes do grupo que não entendem os comandos da mesma maneira. Os participantes não se entendem no momento da definição do problema por diferentes visões ou concepções pedagógicas”

A sociologia das ausências opera mostrando ainda a existência de uma globalização alternativa, contra-hegemônica (ecologia da trans-escalas)

Exibe a existência de aspirações universais alternativas de justiça social, dignidade, respeito mútuo, solidariedade, comunidade e ainda indica que não há uma globalização sem localização e de que tal como há globalizações alternativas também há localizações alternativas. O local existe não apenas sob a forma de expressão de um impacto. Sua redução a esta expressão de um impacto deriva do seu aprisionamento numa escala que o impede de ir além e de aspirar a uma globalização autônoma (p.112-113).

Traços dessa ecologia podem ser percebidos na parceria entre SME e universidade pública local, ao consensuarem um formato avaliativo alternativo regido pelo Pacto de Qualidade Negociada (BONDIOLI, 2004). A proposta estimula processos de negociação entre atores centrais e "periféricos". Coloca atores diferentemente situados em condição de diálogo. As virtudes da chamada subjetividade de fronteira tendem a se fazer presentes e "a criação de obrigações horizontais sobrepõe-se à criação de obrigações verticais, o que significa que a subjetividade é participativa e que geralmente permite que a sua participação seja orientada pelo princípio da comunidade (SOUSA SANTOS, 2005, 351-353).

Igualmente se vislumbra uma similitude ao se recuperar a noção de protagonismos entrecruzados nas diferentes instâncias de "produção" de qualidade da escola pública. Traduzindo melhor: as relações existentes e conflituosas entre escola/NAED/SME ordenam, de alguma forma, a qualidade de ensino que se busca concretizar. Os balizamentos do poder central frente às investidas dos reformadores empresariais da educação evidenciam (ou não) formas alternativas de reagir a soluções prêt-à-porter que descartam saberes dos atores locais em nome de resultados obtidos de forma utilitarista, pragmática e esvaziada dos valores da 
solidariedade e do trabalho coletivo. Os processos de AIP fomentam ações de organização dos coletivos escolares para que construam retórica argumentativa forte em defesa da qualidade social da escola pública.

- Não poderia haver conflitos de entendimento entre as instâncias gestoras do projeto de avaliação institucional. As políticas da secretaria precisam se afinar.

A Ecologia das produtividades consiste na valorização dos sistemas alternativos de produção que partilham uma concepção abrangente de economia, no qual incluem objetivos como participação democrática, equidade social, solidariedade.

O objetivo da sociologia das ausências é revelar a diversidade e multiplicidade das práticas sociais e credibilizar esse conjunto por contraposição à credibilidade exclusivista das práticas hegemônicas. Comum a todas essas ecologias é a ideia de que a realidade não pode ser reduzida ao que existe. Propõem uma versão ampla de realismo, que inclui as realidades ausentes, por via do silenciamento, da supressão e da marginalização, isto é, as realidades que são ativamente produzidas como não existentes.

Observa-se que a AIP busca reorganizar os coletivos da escola de modo a que operem em colaboração, rompendo formas de organização do trabalho nas escolas que mesmo adjetivadas como democráticas, estruturam-se de modo piramidal.

Os dados empíricos, obtidos por meio de entrevistas individuais com os Orientadores Pedagógicos das escolas e complementados por meio de grupos focais com as equipes gestoras, evidenciam que a política de AIP busca expandir o presente, intensificando formas criativas de os atores recriarem em conjunto suas formas de responder (prestar contas) do serviço público que desenvolvem, cujo resultado é dependente do esforço coletivo dos atores que gera demandas que a todos envolve e responsabiliza de forma partilhada.

A inclusão de múltiplos atores no processo de qualificação da escola passa a ser reconhecida como possibilitadora de decisões mais legítimas, subsidiadas pelos saberes que estes fazem circular, antes ignorados ou considerados como forma caótica de expressão e destituídos de cientificidade para orientar os processos decisórios da escola.

Outra marca da sociologia das ausências na AIP expressa-se na ecologia das temporalidades, a qual reconhece que cada unidade escolar, por força de sua historicidade, construirá seu percurso avaliativo fixando metas exequíveis e simultaneamente comprometidas com a imagem objetivo que ajuda a escola a caminhar em seu ritmo próprio, porém aderente aos princípios que regem a política de responsabilização participativa. 
Cada escola da rede, à luz de seu contexto local, da distribuição de forças existentes, presta contas do que fez e do que não pôde fazer (ainda) pela não superação das contradições existentes ou pelo não atendimento (ainda) pelo poder público local das demandas feitas pela escola para que seu projeto educativo possa avançar. O processo de AIP se baseia exatamente na defesa de que cada unidade escolar estabelece seu processo de mudança numa linha de tempo. Essa linha de tempo ganha personalidade e feição próprias em função das relações da escola com o entorno, o que afeta as prioridades traçadas e as estratégias de consecução das metas. Nesse sentido, o caminhar da escola é marcado pela perspectiva de avaliação critério-referenciada, contrariando a cultura classificatória que gera competição e falta de solidariedade.

A ecologia dos reconhecimentos se faz presente nas práticas de acolhimento a segmentos diferenciados (mas não inferiores) para que se posicionem e ajudem a dar concretude à qualidade social que a escola pública deve possuir. A participação como legítima e poderosa estratégia para qualificação do PPP da escola não deve delimitar, acidental ou intencionalmente, que certos atores participem apenas de coisas que correspondam ao que já lhes era devido em função do lugar social que ocupam.

A proposta de AIP revela, ainda que de forma embrionária, a ecologia das trans-escalas. Esta coloca em perspectiva os dados de avaliação externa que chegam à escola e os examina de forma crítica a partir da escala local, ou seja, a comunidade elege as prioridades e metas que sustentam seu projeto educativo, evitando que ele seja enviesado pela lógica da exterioridade.

Há que se lembrar que, nessa relação trans-escalar, a visão colonialista presente na avaliação-como-regulação e que induz a que se descarte a solidariedade como expressão de qualidade do projeto educativo da escola é confrontada. Os atores podem se organizar e criar formas alternativas de responder às exigências do modelo de responsabilização vertical interpelando os desdobramentos que as escolhas presentes nessa forma de avaliar a escola acarretam. Essa nova postura enseja recuperação da capacidade de atuação dos atores, retirando a escola da passividade frente ao que vem de fora como se fosse mera receptora de impactos das políticas, fortalecendo o protagonismo local.

Vemos na AIP traços da ecologia da produtividade, a qual enseja novos processos de trabalho na escola, visando a superar a lógica do eficienticismo. Aderente a essa ecologia, a AIP assume como seu referente avaliativo uma concepção de qualidade social referenciada na formação humana. Assim, a solução da qualidade da escola não estará dependente apenas da revisão do índice de desenvolvimento educacional obtido. Envolve outro olhar para a formação dos 
sujeitos sociais e isso coloca em xeque, inclusive, a função social da escola. Tratase de usar a avaliação-como-emancipação em favor dos direitos dos estudantes à educação no sentido amplo do termo, ultrapassando os limites instrucionais.

$O$ pacto de qualidade negociado entre os multiatores nesta perspectiva ampliada contribui para reconfiguração das práticas e processos relacionais da e na escola. Ao ensejar a inclusão dos atores no processo de pactuação e de deliberação sobre a qualidade desejada, fortalece a comunicação e a cumplicidade desses, promovendo condições de um diálogo mais denso que envolve, simultaneamente, o direito de demandar condições objetivas para que desenvolvam melhor o trabalho pedagógico que querem efetuar em favor de todos os estudantes, bem como a humildade ético-epistemológica para aceitar demandas que requeiram de si mais comprometimento ou rigor com os processos de aprendizagens necessários para que todos os jovens consigam aprender na escola pública.

Cabe realçar que, embora sejam visíveis avanços nas escolas decorrentes do processo de autoconhecimento e reflexão sobre o cotidiano e que confirmam as possibilidades de expandir o presente, no dizer de Sousa Santos, a AIP não se implementou de modo monolítico na rede, observando-se várias críticas dos OPs, ligadas à sobrecarga dos profissionais e à falta de sintonia entre as instâncias gestoras da rede

- Muitos se sentem desobrigados de refletir sobre o pedagógico.

- Penso que não vou dar conta dos processos já iniciados e outra vez pode-se acabar morrendo na praia. Isso já aconteceu antes com outros trabalhos (bons) iniciados na rede.

- Falta de tempo para registrar, tempo para pensar. A avaliação institucional é mais uma atividade na agenda do OP que é demandado em diferentes frentes de trabalho

Analisemos agora os desafios da contração do futuro por meio da sociologia das emergências.

A sociologia das emergências consiste substituir o vazio do futuro segundo o tempo linear (um vazio que tanto é tudo como é nada) por um futuro de possibilidades plurais e concretas, simultaneamente utópicas e realistas, que vão se construindo no presente através das atividades de cuidado (...). O conceito que preside a sociologia das emergências é o Ainda-Não que inscreve no presente uma possibilidade incerta, mas nunca neutra (SOUSA SANTOS, 2006, p.116117). 
A sociologia das emergências explora alternativas e trata de incrementar intervenções humanas engajadas com a construção de outro futuro. Aposta na vitória da esperança em detrimento da frustração. Mas para tal, reconhece a necessidade de conhecer melhor as condições de possibilidade da esperança e definir princípios de ação que promovam a realização dessas condições.

A similitude dessa sociologia com os mecanismos de contrarregulação merece ser enfatizada. $\mathrm{Na}$ contrarregulação, interessa reagir propositivamente ao que está posto pelos sofrimentos que ocasiona às pessoas. A indignação move a decisão de agir e atuar politicamente sobre a realidade. Trata-se do agenciamento das pessoas para a causa comum e que possibilita uma práxis consciente e implicada.

Segundo Sousa Santos, ambas sociologias (da ausência e da emergência) visam a alimentar ações coletivas de transformação social que exigem sempre um envolvimento emocional, seja de entusiasmo ou de indignação. Juntas, se completam e expressam seu inconformismo com o que existe.

A objetividade destas sociologias está dependente da qualidade da sua dimensão subjetiva (...). A corrente fria é a corrente do conhecimento dos obstáculos e das condições da transformação. A corrente quente é a corrente da vontade de agir, de transformar, de vencer os obstáculos. A corrente fria nos impede de sermos enganados; conhecendo as condições é mais difícil nos deixar condicionar. A corrente quente, por sua vez, impede-nos de nos desiludirmos facilmente. $\mathrm{O}$ medo exagerado de sermos enganados acarreta o risco de transformar as condições em obstáculos incontornáveis e com isso, conduzir ao quietismo e ao conformismo. Por sua vez, o medo exagerado de nos desiludirmos cria uma aversão total a tudo o que não é visível nem palpável e, por esta outra via, conduz igualmente ao quietismo e ao conformismo (pp.118-119).

Tanto em Sousa Santos, quando trata das sociologias das ausências e das emergências, como em Freitas et al. (2009), quando constroem o significado de contrarregulação, identificamos a convergência na luta por uma relação mais equilibrada entre experiência e expectativa; entre condição e oportunidade; entre discurso e práxis; entre atuação protagônica e socialconformismo. "Não se trata de minimizar as expectativas, trata-se antes de radicalizar as expectativas assentes em possibilidade e capacidades reais, aqui e agora" (SOUSA SANTOS, 2006, p.119).

A experiência de AIP pode ser interpretada como algo que amplia as possibilidades de transformação da realidade, cuidando do futuro por meio de outro jeito de atuar no presente. Vale-se de princípios como a participação plural, o diálogo pautado em um conhecimento argumentativo, a negociação entre atores assentada numa ecologia das diferenças feita de reconhecimentos recíprocos, 
o gosto pela democracia e o interesse pelo Bem Comum, o bem do comum. Deste esforço compósito, condições técnicas e políticas para a melhoria da escola pública vão sendo engendradas.

"Percebo que gosto de ser mediadora e tenho aprendido a aproveitar tudo que é dito pelo grupo, sintetizar e alavancar a discussão para um ponto além da queixa, permitindo que vislumbremos possibilidades de ação em nosso cotidiano, embora limitadas"

"As reuniōes têm me feito refletir sobre como, na posição de gestora, encaminho determinadas questões da escola e tenho procurado me convencer de que não é possivel resolver tudo. Preciso, juntamente com meus parceiros de trabalho, estabelecer/antever possibilidades de ação, não havendo a garantia de sucesso, mas o real compromisso/ responsabilidade com o PP que juntos construimos e tentamos implementar, contando sempre com a possibilidade dos erros e dos acertos, sem que para isso tenha que haver culpados"

"A noção do poder deve ser pensada historicamente. Queremos que eles (referindo-se às famílias, estudantes, funcionários) se sintam responsáveis, mas a gente (referindo-se à equipe gestora) guarda a chave no bolso, longe do alcance de todos"

"Sinto que crescemos em confiança, conbecimento do outro e da gente mesmo".

A política de AIP assenta-se em valores e princípios distintos dos processos de responsabilização vertical. Isso exige reconhecer a cultura de avaliação instituída e a pressão que as escolas sofrem dos órgãos de regulação externa. É nesse cenário híbrido e tenso que a AIP tenta tornar seus fundamentos inteligíveis aos atores. Para que esse esforço seja exitoso, há necessidade de um trabalho de tradução.

\section{O TRABALHO DE TRADUÇÃO E O DESAFIO DE FAZER FALAR À AVALIAÇÃO}

A tradução é o procedimento que permite criar inteligibilidade recíproca entre as experiências do mundo, tanto as disponíveis como as possíveis, reveladas pela sociologia das ausências e a sociologia das emergências. É, simultaneamente, um trabalho intelectual e um trabalho político, pois visa a criar inteligibilidade, coerência e articulação num mundo enriquecido por uma tal multiplicidade e diversidade (SOUSA SANTOS, 2006).

Pretende colocar em causa a existência de práticas mais adequadas (socialmente falando) para enfrentar os limites da realidade a ser transformada e que exige o concurso dos atores sociais implicados. A complexidade dos problemas a superar desafia os atores a aproximações estratégicas, o que demanda formas inteligíveis de comunicação e negociação. Assim, o trabalho de tradução é sempre um trabalho coletivo, conflituoso e exigente de escuta atenta e respeitosa. 
Na política de AIP, a responsabilidade de tornar inteligíveis os topoi de cada cultura (gestores, professores, famílias, estudantes, funcionários) foi concentrada no OP. Evidentemente, o trabalho que o OP deve liderar para dar consequência à AIP afeta e é afetado pela qualidade dos processos intersubjetivos previamente existentes na escola. O princípio da corresponsabilidade e da liderança alternada encontrará maior ou menor dificuldade de se instalar em cada realidade, de acordo com a confiança relacional existente.

Chamamos de liderança alternada a capacidade que os atores envolvidos na avaliação do PPP da escola devem possuir para se colocar a serviço da causa comum. A titularidade provisória para o trato do problema deriva exatamente da seleção adequada do ator em condição mais adequada para enfrentar o desafio, otimizando as chances de êxito. A auto-organização propicia que os atores possam vivenciar, mantendo-se como coletivo, a situação de ora comandar, ora serem comandados sem que a isso corresponda um desvio de função ou sentimento de subversão da ordem (PISTRAK, 1981).

A criação de uma ambiência democrática associada à confiança relacional é fundamental para tornar possíveis as falas interditadas, por meio da ampliação das zonas de contato entre os atores.

A regulamentação das CPAs tornou obrigatória a ocorrência mensal, no mínimo, da reunião, o que favorecia a ampliação das zonas de contato entre os atores. Segundo Sousa Santos, essas são sempre seletivas. Só o aprofundamento do trabalho de tradução permite trazer para a zona de contato os aspectos que cada saber ou cada prática considerem mais centrais ou relevantes.

Percebemos que a vocalização dos atores, em condição de inserção "periférica" em relação ao centro do poder e do conhecimento, se mostrava tímida e ou quase ausente quando o foco eram os aspectos pedagógicos. Falavam com mais desenvoltura da estrutura da escola, das quadras, da falta de professor, da falta de segurança, das festas, mas silenciavam sobre as questões de aprendizagem, parecendo aceitar o rótulo de ignorantes no quesito. O silêncio parecia ser palavra nesse cenário.

Cabe ressaltar que a mediação do OP não implicava que falasse em nome desses atores. Esperava-se uma escuta sensível dessas vozes, verdadeiramente interessada naquilo que traziam à cena. Mesmo que isso consumisse tempo, mesmo que isso parecesse a alguns como algo supérfluo, posto que ninguém melhor do que os profissionais da escola para dizer o que era bom para os estudantes e para as famílias. Aparece aí o cuidado que Sousa Santos traz ao debate. 
Um cuidado sobre o quando traduzir resulta de uma conjugação de tempos, ritmos, oportunidades. "Sem esta conjugação, a zona de contato tornase imperial e o trabalho de tradução torna-se uma forma de canibalização. Nem sempre as culturas oprimidas estão naturalmente prontas para o diálogo. Há diferentes temporalidades em cena" (p.132).

Uma boa mediação requer capacidade para criar zonas de contato densas para que aspectos substantivos relativos à qualidade da escola pública aflorem de forma polifônica.

Zonas de contato aprofundam-se processualmente e são construídas na experiência do conviver. Resulta que, quanto mais for exercitado este "estar junto" em prol de algo maior que nos desafia e nos une, o trabalho de tradução vai identificando os topoi que são adequados à zona de contato e à situação de tradução e ajudando a realizar a gestão do silêncio e a tradução do silêncio (tanto do impronunciável quanto os diferentes ritmos).

"Preciso que eu mesma seja capaz de me perceber como mais uma parceira, ainda que com responsabilidades especificas de quem é gestor. Não tenho a obrigação de ter a resposta para tudo, a solução mágica para resolver problemas que vão desde o parafuso que solton da cadeira até a condição de vida do garoto que sobrevive, apesar da família".

"Talvez estejamos matando muitos touros à unba todos os dias na escola e o desgaste esteja sendo grande demais"

"Apesar do muro de lamentações, percebo um movimento de busca de soluções e o desejo de resolver as questões que se apresentam no cotidiano das escolas e que vão nos engolindo dia a dia".

Observa-se na AIP uma valorização do movimento formativo da escola na direção da qualidade e isso a coloca em condição de diálogo propositivo com o poder público local para que este garanta condições objetivas para que o pacto de qualidade negociado atinja determinadas metas. Metas propostas e assumidas pela escola e não necessariamente aquelas fixadas externamente.

Qualidade é transação, isto é, debate entre indivíduos e grupos que têm um interesse em relação à rede educativa, que têm responsabilidade para com ela, com a qual estão envolvidos de algum modo e que trabalham para explicitar e definir, de modo consensual, valores, objetivos, prioridades, ideias sobre como é a rede (...) e sobre como deveria ou poderia ser (BONDIOLI, 2004, p. 14).

Considerando que a AIP estava ancorada em uma concepção de avaliação erigida em categorias fortes (participação, negociação), parece licito esperar que, assumida como política de governo, os gestores centrais tivessem clareza dos compromissos inerentes a um processo de qualificação da escola pública que se arvora democrático e, portanto, pensado/deliberado coletivamente. 
Essa responsabilidade não só é da escola, naquilo que lhe é devido, mas também é relativa ao que a escola necessita dispor para garantir a exequibilidade do seu projeto. Daí o sentido de um "pacto" com múltiplos atores: da escola para com seus estudantes; da escola consigo mesma; da escola com os gestores do sistema escolar; e dos gestores do sistema para com a escola (FREITAS et al, 2009)

"As mudanças só ocorrerão a partir das desacomodações dos paradigmas internalizados em cada profissional que compõe a equipe. Seja ela equipe de funcionários, secretaria, professores ou até mesmo o pessoal que compõe a equipe de gestão de cada escola"

"Desejo que sejamos menos imediatistas e consigamos redimensionar nosso olhar para o objetivo traçado em nosso PP percebendo que nossas ações são coordenadas, interdependentes e deste modo podemos e devemos contar uns com os outros para atingir nossos objetivos"

O diálogo entre diferentes atores/instâncias carece de uma teoria de tradução para legitimar os acordos firmados e potencializar as intervenções no chão da escola. Considerando a escassa experiência de participação de segmentos diferenciados (porém não inferiores) no processo de melhoria da escola pública, admite-se que a escuta dessas vozes nos remete ao cerne da teoria da tradução. Há que se aprender a ouvir, há que se aprender a falar com, há que se esforçar por traduzir sem trair.

Estando a AIP sob a responsabilidade de mediação de um ator social, deste se requereria a sensibilidade para a escuta das expectativas e opiniões dos demais segmentos e coragem para torná-los inteligíveis aos demais atores, dentro e fora das escolas. Aqui observamos um problema de escala que pode afetar a teoria da tradução que subjaz a AIP nessa rede, especialmente, no que tange à opção pela CPA como instância organizadora dos atores. No âmbito local (escola), o esforço de tradução pode ser mais facilmente concretizado graças ao controle social que a comunidade exerce em nome do pacto de qualidade. Explicitadas as prioridades do projeto educativo que defendem face aos requerimentos do entorno, cada comunidade escolar se implica, se responsabiliza pela concretização dessas na prática, resultando consequências.

O fato de cada escola atribuir-se a liberdade de delinear a sua própria fisionomia educativa, levando em conta seu contexto, limites e virtudes; o fato de que tais escolhas se tornam públicas e socializadas, ou seja, o direito de criar sua fisionomia está acompanhado do dever de "tornar público" o seu projeto; e, finalmente, evidencia-se o caráter "ético" dessa operação na medida em que, uma vez público, toma o sentido de uma promessa, de uma admissão de responsabilidade para realizá-lo. (BONDIOLI, 2004, p. 25) 
No terreno da escola, parece mais fácil defender determinadas concepções de qualidade, mas há que se avançar em outras escalas. Ou seja, a partir do pacto firmado, este reclama por esforços de tradução junto a outras instâncias da rede de ensino que igualmente precisam desenvolver sua capacidade de escuta dos topoi da escola, discutindo-os, de modo respeitoso e argumentativo, para que novos olhares afetem os processos deliberativos nesses níveis. Nesses espaços, a disputa contra hegemônica é mais complexa se considerarmos a pressão que os gestores centrais têm sofrido para que alinhem as escolas aos referenciais de qualidade mercadológica. Observa-se que a coerência epistemológica entre o que diz a política e as decisões que faz circular é de vital importância e impõe aos atores alocados em lugares decisórios, compromissos com os acordos construídos na escola. Cabe-lhes, no entanto, intervir toda vez que esses acordos colocarem em risco as responsabilidades da rede com as aprendizagens (ampliadas) das crianças. Em nome dessa qualidade socialmente referenciada, a teoria da tradução perpassa outras escalas, dentro e fora da rede de ensino, inclusive com os órgãos de regulação externa.

Dado que não há uma prática social ou um sujeito coletivo privilegiado em abstrato para conferir sentido e direção à história, o trabalho de tradução é decisivo para definir, em concreto, em cada momento e contexto histórico, quais as constelações de práticas com maior potencial contra-hegemônico (SOUSA SANTOS, 2006, p.127-129).

- O coletivo é um grupo de indivíduos. Pensar e agir coletivamente para alguns dá muito trabalho, mas estamos descobrindo que é muito mais produtivo.

- Melhorou muito nos últimos anos. Todos podem colocar suas posições, discordâncias seja no grande grupo ou à gestão. Ainda há desrespeito por parte de alguns. Considero como avanço, a forma como a maior parte dos professores e gestão elege, planeja e avalia os trabalhos, mas nem todos, penso que apenas a metade, considera a opinião dos alunos no processo.

- Sou apenas uma das mediadoras do trabalho coletivo, não a única. Me acho responsável para nos mantermos fiéis ao que projetamos.

- O dia a dia nas escolas nos ensina muito. Acostumei-me a separar divergências pedagógicas e relacionamento pessoal. Não podem ser misturadas estas coisas e nem abalar as relações.

- Temos dificuldades de lidar com conflitos e com contradições para chegarmos a pontos comuns, decisões realmente coletivas.

- Sinto que, às vezes, me omito. Sinto que o grupo me isola também. Tudo é muito complexo. 


\section{A COMPLEXIDADE DA IMPLEMENTAÇÃO DA AIP EM \\ CENÁRIOS DENEGADORES DA QUALIDADE SOCIAL DA ESCOLA PÚBLICA}

Nunca foi tão grande a discrepância entre a possibilidade técnica de uma sociedade melhor, mais justa e solidária e sua impossibilidade política. Os novos tempos criam-nos a sensação de estarmos vertiginosamente parados, sem condição de reagirmos aos crescentes ataques à escola pública. A reinvenção de possibilidades que nos ajudem a expandir o presente e a contrair o futuro é um desafio que mobiliza a todos os que lutam por um projeto educativo socialmente pertinente.

A AIP, conforme mostra a experiência na rede municipal de Campinas, se revelou uma estratégia potente para reconfigurar o lugar da escola no complexo processo de produção de qualidade. Contribuiu para devolver a titularidade aos atores locais no delineamento dos contornos do projeto educativo e deste modo ensejou a criação de espaços coletivos de pactuação, atuação e avaliação da qualidade negociada.

A formulação de uma agenda política alternativa levou os atores a movimentos interessados em superar a inação, o conformismo. "Todo o conhecimento é uma prática social de conhecimento, ou seja, só existe na medida em que é protagonizado e mobilizado por um grupo social, atuando num campo social em que atuam outros grupos rivais protagonistas ou titulares de formas rivais de conhecimento" (SOUSA SANTOS, 1996, p 17).

A constituição de espaços sociais/institucionais que reaproximem os coletivos é condição mínima para permitir que segmentos excluídos de uma participação cidadã possam ser recolocados nos processos decisórios, pronunciando-se a serviço de quem e do quê disputam a agenda política, alterando a constelação de práticas em condição de hegemonia.

Admitindo-se que políticas avaliatórias sejam implementadas sem reflexão à jusante e desconsiderando as repercussões sobre as pessoas (alunos/ famílias/profissionais da educação), podemos afirmar que se coadunam com a chamada aplicação técnica do conhecimento, posto que quem as aplica está fora da situação existencial em que incide a aplicação, não sendo afetado diretamente por ela. 
A aplicação técnica assume como única a definição da realidade dada pelo grupo dominante e força-a. Escamoteia os eventuais conflitos e silencia as definições alternativas. A aplicação do know how técnico torna dispensável, e até absurda, qualquer discussão sobre um know how ético. (...) A aplicação é unívoca e o seu pensamento é unidimensional. Os saberes locais ou são recusados ou são funcionalizados e, em qualquer caso, tendo sempre em vista a diminuição das resistências ao desenrolar da aplicação (SOUSA SANTOS,1996, p.19).

Nessa perspectiva, os decisores políticos e os atores sociais são expostos a uma forma de avaliar respaldada em um conhecimento tido como certo e rigoroso, sobre a qual não cabe contestação, posto que neutra. A aplicação técnica desse conhecimento garante soluções eficazes, inequívocas e consensuais porque apresentadas sem alternativa.

Diferentemente, a AIP na rede municipal de Campinas comportou-se como uma forma de aplicação edificante da ciência, pois ocorreu numa situação concreta em que quem aplica está existencial, ética e socialmente comprometido com o impacto da aplicação; os meios e os fins não estavam separados e a aplicação incidiu sobre ambos; a aplicação foi um processo argumentativo e a adequação, maior ou menor, da aplicação, residiu no equilíbrio, maior ou menor, das competências argumentativas entre os grupos que lutam pela decisão do conflito a seu favor; buscou revelar argumentos dos grupos com menor poder e tornar legítimos e credíveis seu uso, "deslegitimando as formas institucionais e os modos de racionalidade em cada um dos contextos em que tais formas ou modos promovem violência em vez da argumentação e o silenciamento em vez da comunicação; o estranhamento em vez da solidariedade (SOUSA SANTOS,1996, p.21)

Consideramos isso um avanço. Mas não se trata apenas de defender a aplicação edificante do conhecimento, mas de disputar propositivamente de que conhecimento se está falando. Ou seja, que concepção de qualidade é essa que se avalia? Por quem, para quê e para quem deve ser avaliada?

Isso nos remete à necessidade de tornar inteligível o que se entende por qualidade social na educação em busca de formas alternativas de avaliação que permitam captar esse fenômeno em sua multidimensionalidade. Isso exigirá bastante engajamento e instrumentalização ético-epistemológica dos coletivos escolares para ajudarem a traduzir na prática os significados de uma educação referenciada na formação humana.

Há que correr riscos para traduzir sem trair os princípios que regem um projeto educativo de alta envergadura social. Traduzir produzindo zonas de contato densas em que se busque o diálogo sem que se elimine o dissenso argumentativo. $\mathrm{E}$, uma vez concebidos processos de avaliação que busquem a inclusão de atores e que ambicionem uma educação mais abrangente a ser assegurada como direito 
social para todos os jovens, há que se cuidar de modo diuturno da implementação desta política de avaliação, compreendendo as tensões que esta terá que suportar e superar para se configurar como possibilidade alternativa em tempos tão sombrios como os em que vivemos, nos quais o individualismo, a competitividade e a meritocracia parecem reinar absolutos.

\section{REFERÊNCIAS}

AFONSO, A. J. Para uma conceptualização alternativa de accountability em educação. Edu. Soc., Campinas, v. 33, n. 119, p. 471-484, abr.-jun. 2012.

BONDIOLI, Anna (Org.). O Projeto pedagógico da creche e a sua avaliação: a qualidade negociada. Campinas - SP; Autores Associados, 2004.

SANTOS FILHO, Serafim et al Avaliação como dispositivo de humanização em saúde. Considerações metodológicas. In: CAMPOS, R. O. \& FURTADO, J. P. (org.) Desafios da avaliação de programas e serviços em saúde. Campinas, SP: Editora da Unicamp, 2011, p. 257-278.

FREITAS, L. C., et al. Avaliação Educacional: caminhando pela contramão. Petrópolis-RJ: Vozes, 2009.

PISTRAK. Fundamentos da Escola do Trabalho. São Paulo: Brasiliense, 1981.

SORDI, M. R. L.; FREITAS, L.C. Responsabilização Participativa. Revista Retratos da Escola, Brasília: v. 7, n. 12, p. 87-99, jan. /jun. 2013.

SORDI, M.R.L Desafiando a hegemonia do campo da avaliação da qualidade das escolas: a avaliação institucional participativa como estratégia. Tese (Livre docência) -UNICAMP, Campinas, 2018.

SOUSA SANTOS, B. Para uma pedagogia do conflito. In: SILVA, H.L.; AZEVEDO, J.C.; SANTOS, E.S. Novos mapas culturais, novas perspectivas educacionais. Porto Alegre: Sulina, 1996. 
SOUSA SANTOS, B Não disparem sobre o utopista. In: SOUSA SANTOS, B. A crítica da razão indolente. Contra o desperdício da experiência. V 15 ed, Cortez, 2005.

SOUSA SANTOS, B. A gramática do tempo. Para uma nova cultura política. SP: Cortez, 2006.

\section{Mara Regina Lemes Sordi}

Doutora em Educação pela Universidade Estadual de Campinas (UNICAMP), pós doutorado na Pontifícia Universidade Católica do Rio de Janeiro (PUCRJ). Livre Docente em Avaliação pela Faculdade de Educação da UNICAMP. Professora do Departamento de Estudos e Práticas Culturais (DEPRAC) da Faculdade de Educação da UNICAMP. Docente permanente do Programa de Pós-Graduação em Educação da mesma instituição. Coordenadora do Laboratório de Observação e Estudos Descritivos (LOED) da Faculdade de Educação da UNICAMP. Desenvolve e coordena estudos e pesquisas sobre avaliação educacional tanto na educação superior como educação básica. E-mail: maradesordi14@gmail.com 